\title{
FILOSOFÍA Y EL PROBLEMA DE DIOS EN XAVIER ZUBIRI ${ }^{1}$
}

\author{
ESTEBAN VARGAS \\ Pontificia Universidad Católica de Valparaíso
}

\begin{abstract}
RESUMEN: El trabajo intenta dilucidar en qué consiste «el problema de Dios» como problema filosófico en Xavier Zubiri. Para ello, dividimos la exposición en tres partes. En primer lugar, hay que aclarar si es posible tratar «filosóficamente» el tema de «Dios». Desde Zubiri, ello es posible si estudiamos el «problema» de Dios como algo «dado» sentientemente, y no a «Dios» entendido como un ser supremo más allá del mundo. En segundo lugar, hay que analizar en qué consiste «el problema de Dios» para Zubiri. ¿Se trata acaso de que el problema de Dios nos está «dado» como punto de partida en la aprehensión primordial? ¿O será acaso que el «problema de Dios» es aquello que puede llevarnos o no «hacia» Dios? Finalmente, en tercer lugar, hay que analizar las diversas actitudes y soluciones ante el «problema de Dios» como el ateísmo, el agnosticismo o el teísmo. Zubiri mismo defendió una posición teísta y estableció una prueba racional que fue modificando en sus últimos años.
\end{abstract}

PALABRAS CLAVE: Zubiri, Dios, filosofía, problema, fundamentalidad.

\section{Philosophy and the Problem of God in Xavier Zubiri}

ABSTRACT: This paper attempts to clarify what constitutes «the problem of God» as a philosophical problem with Xavier Zubiri. To do this, we divide the paper into three parts. First, we should clarify if possible to study «philosophically» the subject of «God». From Zubiri, this is possible if we study the "problem» of God as something "given» sentiently, not «God» understood as a supreme being beyond the world. Second, we have to analyze what is the "problem of God" according to Zubiri. Do we mean that the problem of God is "given» as a starting point in the primordial apprehension? Or might it be that the "problem of God» is something that can lead or not "towards" God? Finally, thirdly, we must analyze the various attitudes and solutions to the "problem of God" as atheism, agnosticism or theism. Zubiri defended himself a theistic position and established a rational proof that was gradually modified in his later years.

KEY WORDS: Zubiri, God, philosophy, problem, fundamentality

\section{INTRODUCCIÓN}

El problema de Dios es uno de los problemas fundamentales de la filosofía. Ya sea para demostrarlo o negarlo, Dios ha estado siempre presente en las preocupaciones filosóficas. Al respecto han existido múltiples maneras de estudiar el problema. Por ejemplo, la Filosofía Medieval ha pretendido demostrar «racionalmente» la existencia de Dios partiendo, en cierto modo, o bien desde los datos de los «sentidos» (por ejemplo, las cinco vías de santo Tomás de

1 Este artículo fue posible gracias a un Proyecto Fondecyt Regular $\mathrm{N}^{\circ} 1140922$ llamado "Ciencia y realidad en Zubiri», la Fundación Xavier Zubiri de Madrid y la Università degli Studi di Bari Aldo Moro donde se realizó el Seminario Xavier Zubiri: una filosofía per l'uomo (1983-2013). Este artículo es una exposición muy reelaborada de una ponencia presentada en dicho Seminario. 
Aquino) o bien desde los datos de la «pura razón» (por ejemplo, el argumento ontológico de san Anselmo). Esta tarea se continuó, a su modo, en la Filosofía Moderna, por ejemplo, en Descartes y Leibniz, por nombrar algunos. Es lo que constituyó el tema de la Teología natural y la Teodicea. Sin embargo, ya desde la misma época moderna hasta nuestros días, se empezó a cuestionar el papel que los antiguos daban a los sentidos y la razón en el conocimiento. Esto ha afectado directamente a la manera cómo se intentaba conocer a Dios. Por ejemplo, Kant, en la Crítica de la Razón Pura, parecía haber destruido la posibilidad de un conocimiento racional de Dios. Se intentaron, por ello, otras vías, centradas ahora en algunos aspectos del hombre como la moral y los sentimientos. Fue, por ejemplo, la tarea del mismo Kant y de Schleiermacher. Pero esto tampoco pareció prosperar en demasía. Poco a poco se empezó a cuestionar los diversos conceptos que se habían obtenido sobre Dios y se los intentó explicar como surgiendo desde los diversos deseos y necesidades del hombre. Fue, en cierta forma, lo que hicieron Feuerbach, Marx y Nietzsche, por nombrar algunos. En la medida en que el apego a los sentidos aparece en las ciencias y en la filosofía (positivismo), en esa misma medida va desapareciendo el tema del conocimiento de Dios como conocimiento racional legítimo. No obstante ello, el tema de Dios comienza a recobrarse curiosamente desde el mismo positivismo. Se empieza a estudiar ahora no el conocimiento de las vías «racionales» hacia Dios, sino el «hecho» social e histórico de las religiones. Alguien podrá negar la existencia de Dios, pero no podrá negar la existencia de las religiones en el mundo, las cuales nos muestran determinadas creencias, cultos, etc. Fue el comienzo de las ciencias y la filosofía de la religión. Tenemos así diversas posturas que se han tomado sobre Dios, desde las diversas vías racionales, pasando por el ateísmo, hasta el estudio de las religiones y de lo religioso. Después de tener en cuenta la breve historia ya expuesta, surgen varias preguntas: ¿es posible un conocimiento de Dios? ¿Qué relación hay entre Dios y las religiones? ¿Tenemos experiencia sensible o vital de Dios? ¿Son las diversas posturas ante Dios meros actos arbitrarios de voluntad?

Éste es, más o menos, el horizonte intelectual en donde se sitúa el filósofo español Xavier Zubiri. Este pensador ha investigado el problema de Dios en varias obras y cursos a lo largo de su vida. En primer lugar, en su libro Naturaleza, Historia, Dios, que recoge los escritos publicados hasta el año 1944, donde aparecen dos artículos importantes; «Introducción al problema de Dios» (en realidad publicado en 1964) y «En torno al problema de Dios». En segundo lugar, el curso de 33 lecciones llamado precisamente «El problema de Dios» (1948-1949), hoy inédito. En este extenso curso se desarrolla en más de dos mil páginas el pensamiento de Zubiri en torno al problema de Dios, estudiando, por ejemplo, este problema en la historia de las religiones. En tercer lugar, en sus cursos de los años sesenta, que fueron grabados y corregidos por el propio Zubiri, se desarrolla por primera vez una exposición en tres partes (o trilogía) sobre el «problema de Dios» en tres cursos distintos. La primera parte la constituye el curso «El hombre y el problema de Dios» (1968), aún inédito. La segunda parte se llama «El problema filosófico de la historia de las religiones» 
(1965) y, en fin, la tercera parte se llama «Reflexiones filosóficas sobre algunos problemas de teología» (1967), también inédito, donde Zubiri desarrolla sus ideas sobre el cristianismo. Son cursos independientes, expuestos no en una secuencia programática, pero que responden al plan de una trilogía que quedó expresado en un índice posterior que elaboró Zubiri para hacer de estos tres cursos un solo libro. Este plan no se realizó porque, en 1971, Zubiri dictó un nuevo curso llamado «El problema teologal del hombre: Dios, religión, cristianismo", (recientemente lo hemos publicado en forma completa junto a Antonio González) el cual contiene el desarrollo completo de esa trilogía. Esta trilogía Zubiri posteriormente quiso redactarla como libro. Para ello, la primera parte de ese curso de 1971, notablemente ampliada y corregida, fue expuesta en 1973, en Roma, con el nombre de «El problema teologal del hombre: El hombre y Dios». Tomando como base este curso, Zubiri empezó a redactarlo como libro llegando a concluir, en forma mecanografiada, sólo la primera parte, dejando en forma manuscrita el inicio de la segunda parte. La primera edición del libro El hombre y Dios fue hecha por Ignacio Ellacuría, quien la publicó en 1984, es decir, sólo un año después de la muerte de Zubiri. Esta edición no contempló esta segunda parte manuscrita, ya mencionada, tal vez por la dificultad de su lectura. Además, completó la Segunda Parte con un texto sin título, que nosotros, en la última edición, hemos llamado «El despliegue del problema de Dios». Ellacuría lo creyó posterior al curso de 1973, razón por la cual no publicó la segunda parte del curso de Roma. Varias razones parecen indicar que esto es un error²; la "última redacción» de Zubiri de la segunda parte de El hombre y Dios está contenida en el texto manuscrito y en el curso de Roma, no en el texto «El despliegue del problema de Dios».

Teniendo todo esto en cuenta, hay que señalar que en este escrito intentamos dilucidar en qué consiste «el problema de Dios» en la filosofía de Xavier Zubiri, tomando en consideración las últimas obras de Zubiri sobre el tema y, en especial, la nueva edición de El hombre y Dios. Intentamos demostrar que desde el pensamiento de Zubiri se puede filosofar sobre Dios (lo que podríamos llamar una filosofía teológica o teologal) desde una perspectiva algo distinta de las clásicas áreas filosóficas de Teología natural y Teodicea. Para realizar esta investigación, dividiremos el escrito en tres partes:

1. ${ }^{\circ}$ ¿Es posible «filosofar» sobre Dios? Debemos investigar, ante todo, desde Zubiri, qué se entiende por filosofía y cuáles son las condiciones que tendría un posible «filosofar» sobre Dios.

$\left.2 .^{\circ}\right)$ Supuesto lo primero, ¿'en qué consiste concretamente el estudio filosófico sobre «Dios»? Para Zubiri, esto nos lleva al análisis del «problema de Dios» o problema teologal.

3..$^{\circ}$ Finalmente, hay que averiguar en qué consiste las diversas actitudes o posiciones en respuesta al problema de Dios.

2 Cfr. la «Presentación» de ZubIRI, X. (2012). El hombre y Dios. Nueva Edición. Madrid: Alianza. 
Serán los tres puntos que tendremos que desarrollar.

\section{1. «FILOSOFÍA» SOBRE DIOS}

Ante todo, hay que averiguar si es posible tratar «filosóficamente» el tema de Dios, desde el pensamiento de Zubiri. Todo esto depende de qué se entiende aquí por "filosofía» y qué se entiende por «Dios». Atendamos, ante todo, en este primer apartado, al primer punto: ¿de qué trata la filosofía? Hay un pasaje que podría ser esclarecedor, y que aparece en su curso, ya editado como libro, llamado Los problemas fundamentales de la metafísica occidental, donde Zubiri se refiere en general a la metafísica como estudio de lo transcendental, que es el tema formal de la filosofía:

«Hay cosas que no percibimos, no porque estén ultra, allende las cosas que inmediatamente encontramos, sino justamente al revés: porque son algo que está en toda percepción y en toda cosa (...) estar allende para la metafísica no significa ir a cosas que estén ultra, sino ir a lo diáfano, a aquello que por su diafanidad está inscrito en todo lo obvio que el hombre encuentra en sus actos elementales» ${ }^{3}$.

Zubiri dice, por una parte, que hay algo (lo transcendental) que está «en toda percepción». ¿Qué significa esto? Dicho negativamente, parece claro que hay cosas que «no» están presentes en toda aprehensión o percepción como, por ejemplo, las piedras, las montañas, etc. Estas «cosas» pueden aparecer y desaparecer de nuestra aprehensión. La filosofía de Zubiri, en cambio, trata de «temas» que parecen «estar siempre presentes» y que no podemos eludir como «lo que es» (ser), la realidad, el tiempo, la historia, la conciencia, etc. Dejemos de lado aquí la imprecisión de hablar de «temas» y de hablar de su "estar presentes». Lo importante es atender a que estos conceptos, entendidos filosóficamente, parecen estar presentes en forma ineludible. Constituyen precisamente lo «obvio». No son temas que están delante de nosotros y que pueden desaparecer de nuestra aprehensión.

Zubiri dice también, por otra parte, que lo transcendental es algo que está presente "en toda cosa». Aquí "cosa» son las realidades que tenemos presentes. La filosofía estudia, pues, aquello «esencial» que constituye, de algún modo, a todo. Los diversos «temas» de la filosofía de que hablamos antes no son «cosas presentes», sino diversos aspectos «transcendentales» de todo lo aprehendido. Se puede profundizar en cada uno de estos aspectos, pero cada uno de ellos nos lleva tarde o temprano a los demás. Se pueden distinguir conceptualmente, pero sin separarse, como lo cóncavo y lo convexo. Por ejemplo, se puede meditar la relación entre la realidad y la historia. Así, se podría estudiar qué modo de «realidad» posee la historia y, recíprocamente, meditar la conceptuación de la realidad «históricamente».

Ahora bien, de todos estos «temas» se puede buscar cuál es el fundamental, cuál es el primero formalmente hablando, una especie de filosofía primera. En

3 ZUBIRI, X. (1994). Los problemas fundamentales de la metafísica occidental. Madrid: Alianza, p. 19. 
el caso de Zubiri, el tema formal de la filosofía es la «realidad». La realidad es el transcendental primero ${ }^{4}$. Todos los temas filosóficos están relacionados y son aspectos transcendentales en tanto que son momentos fundados en la realidad.

De este modo, considerando lo anterior, un posible estudio «filosófico» sobre Dios, desde Zubiri, debería cumplir con estos aspectos ya señalados. Así:

a) «Dios» (sea ello lo que fuere) debe ser algo presente, «de algún modo», «en toda percepción» (aprehensión). No sería algo que se aprehende ocasionalmente, a veces sí a veces no. El reto filosófico, entonces, es descubrir a Dios en toda acción o percepción humana. La experiencia de Dios no sería ocasional, algo que sólo ocurriría, por ejemplo, el día domingo, en alguna calamidad, en el ejercicio de un determinado acto moral, religioso o piadoso, etc.

b) Habría que meditar qué relación tiene Dios con la realidad como transcendental primero. Para Zubiri, Dios, de cara a la aprehensión, posee ese modo de realidad que es ser «realidad-fundamento» o «realidad fundamental», como tendremos que ver a continuación. Dios, por ser realidad fundamental, estaría, de algún modo, en toda cosa y no sólo, por ejemplo, en lo sagrado.

\section{Filosofía teológica o teologal: anÁlisis del problema de Dios}

Zubiri busca analizar en qué consiste «Dios» como algo que, de algún modo, «se hace presente», lo cual es un punto filosófico de partida para toda investigación ulterior. Sólo así puede surgir una auténtica filosofía teológica o filosofía teologal, como diría quizá Zubiri. Ahora bien, el término «Dios» en Zubiri parece significar, al menos, tres cosas relativamente distintas.

$\left.1 .^{\circ}\right)$ El Dios de una determinada religión o filosofía. Por ejemplo, entender Dios como ser supremo transcendente al mundo. Esta concepción de Dios no es punto de partida para el filosofar.

$2 .^{\circ}$ ) Dios como realidad absolutamente absoluta, por tanto, Dios como «persona». Es la noción de Dios a la que llegará Zubiri, pero, a mi juicio, no es tampoco punto de partida.

3. ${ }^{\circ}$ Dios como "problema». «Dios es el título de un magno problema ${ }^{5}$ nos dice al comienzo de la redacción final de El hombre y Dios de 1983. Zubiri, como hemos señalado, usa muchas veces la expresión «el problema de Dios». El análisis de lo que mienta esta expresión sí representa para Zubiri el punto de partida para el filosofar. Sin embargo, la expresión se presta a equívocos pues esto puede entenderse, a su vez, de muchas maneras.

4 Zubiri, en un curso inédito llamado «Estructura de la metafísica» de 1969, así lo indica: «Entiendo por transcendental primero aquel momento transcendental que es el fundamento de todos los caracteres transcendentales y al cual se refieren formalmente éstos. Y, en este sentido, digo, realidad no es sólo transcendental sino que es el transcendental primero» (ZubiRI, X. (1969). «Estructura de la metafísica», Archivo Zubiri, p. 128).

5 Zubiri, X. (2012). El hombre y Dios, op. cit., p. 21. 
a) En primer lugar, la expresión «el problema de Dios» no se refiere a que sea Dios quien tenga un problema. Es más bien el problema de cómo el hombre hace su realidad. En este sentido, parece mejor la expresión «el problema teologal del hombre» que también Zubiri utiliza algunas veces. En una anotación al margen del escrito precisamente llamado «El problema teologal del hombre», recién reeditado, Zubiri anota: «Es el hombre quien es problema ${ }^{6}$, tal vez, viendo la dificultad de la expresión ya señalada.

b) En segundo lugar, la expresión «el problema de Dios» puede referirse al problema que «conduce» o nos lleva a Dios. "Dios» se entendería aquí como una "posible» respuesta al "problema de Dios», por ejemplo, entender a Dios como en el segundo sentido antes expuesto, a saber, como realidad absolutamente absoluta. Pero, para Zubiri, «el problema de Dios» es algo que acontece en todos; teístas, agnósticos, ateos, etc.

c) Por todo ello, para que sea punto de partida, se trata de entender esta expresión en tanto apunta a la aprehensión del problema de Dios «pero en tanto pro-blema». ¿Qué es un problema? En un problema estamos siempre lanzados «hacia» algo. Si nos preguntáramos, por ejemplo, por qué la mesa es dura, el problema nos remite a una posible composición corpuscular de la materia, hacia sus moléculas y su distribución, etc. Lo normal es que siempre pongamos más atención hacia «aquello» a que vamos arrojados y no al «hacia» mismo, es decir, al carácter de problema «en tanto problema». El análisis de este problema «en tanto problema», como hemos señalado, nos tiene que apuntar a algo de lo cual todos «ya» tenemos acceso.

Por otra parte, hay que tener en cuenta que la expresión «el problema de Dios» no aparece en la última redacción sino hasta el comienzo de la Segunda Parte manuscrita recién publicada, en un capítulo llamado «El problema en sí mismo». Zubiri, además, en la redacción final de El hombre y Dios de 1983, agregó un apartado nuevo que no estaba en el curso de 1973 llamado "Problematismo de la fundamentalidad». Tal vez, esta omisión de la expresión «el problema de Dios» en la Primera Parte no sea casual sino que al "problema de Dios» haya que llamarlo en rigor «el problema de la fundamentalidad» o «el problema de la realidad-fundamento», para no caer en la confusión de entender esta expresión en el segundo sentido antes señalado, a saber, como aquello que conduce o nos lleva a Dios. Volveremos más abajo sobre esta posible corrección de Zubiri.

¿En qué consiste, pues, el carácter «problemático» de Dios o de la «fundamentalidad» del hombre? ¿De qué manera Dios le está ofrecido al hombre como pro-blema?

El análisis del problema de Dios o fundamentalidad, como punto de partida, posee básicamente tres pasos:

\footnotetext{
6 Ibid., p. 3.
} 


\subsection{Diferencia entre lo real $y$ «la» realidad}

Al hombre, por su inteligencia sentiente, se le presentan diversas cosas reales con las cuales hace su vida. Estas cosas reales poseen un momento transcendental, por el cual, son algo «más» que el contenido de lo que se presenta. «Estamos con las cosas, pero donde estamos con ellas es en la realidad» ${ }^{7}$. La realidad como formalidad es «más» que sus contenidos, aunque no es un «más» sin ellos. Este momento de «más» domina, tiene «poder» sobre sus contenidos. Este poder de lo real, domina, se impone, lanzándonos a tener que realizarnos.

\subsection{Religación a «la» realidad o al poder de lo real}

El hombre para poder realizarse se apoya «en» la realidad en tanto realidad como fundamento. La realidad como fundamento no es algo que meramente esté ahí, no es una «realidad-objeto», sino que nos impele a realizarnos. "Esta peculiar ligadura es justo religación ${ }^{8}$. El hombre se encuentra religado al poder de lo real. Esta fundamentalidad de lo real (o realidad-fundamento) a la que el hombre está religado posee un carácter último, posibilitante e impelente.

a) "La» realidad es "última», en tanto que el hombre hace su vida "en» ella (es el fundamento último de todo lo real en tanto real). Es la base del argumento cosmológico de Zubiri ${ }^{9}$.

b) Es «posibilitante» en tanto hace su vida «desde» ella (es el fundamento último de nuestras acciones).

c) Finalmente, es «impelente», en tanto hace su vida "por» ella (es un fundamento «ineludible»; en toda acción humana se debe tomar opción por ese fundamento).

La fundamentalidad de lo real es el fundamento impelente último de la realidad y de mis acciones. A esta fundamentalidad, Zubiri la llama «Dios», pero sólo «nominalmente». Lo dice, por ejemplo, en el primer final de El hombre y Dios que en última instancia tachó: «Al comienzo de la investigación llamaremos Dios al fundamento último, posibilitante e impelente de la articulación, digámoslo así, de las cosas reales en "la" realidad»" También Zubiri lo dice en la última versión manuscrita de la Segunda Parte: «El problema de Dios tiene estos tres momentos: nominal, real y accesible» ${ }^{11}$. ¿Qué significa llamar aquí a Dios o al problema de Dios en forma «nominal»? Se trata de que lo que describimos como fundamentalidad (o la fundamentalidad en su carác-

\section{Ibid., p. 88}

8 Ibíd., p. 98.

9 Sobre este argumento, cfr. GonzÁLEZ, A. (2005), «La vía cósmica hacia Dios según Zubiri», The Xavier Zubiri Review, 7, pp. 91-107; SolaRI, E. (2009), «El argumento cosmológico de Zubiri», Revista Filosófica, Vol. 65, pp. 115-141.

10 Zubiri, X.. (2012). El hombre y Dios, op. cit., p. 116.

11 Ibid., p. 121. 
ter problemático) puede llamarse por ahora nominalmente «Dios», por cuanto este término, en la historia de las religiones, parece usarse en el sentido de ser fundamento último, posibilitante e impelente ${ }^{12}$. No se trata de introducir todos los sentidos del término «Dios» en esta descripción primaria del hecho de la religación como, por ejemplo, Dios en tanto ser supremo transcendente al mundo, creador, etc. No parece casualidad, entonces, que en la Primera Parte de la última redacción de 1983 de El hombre y Dios no aparezca la expresión «problema de Dios» salvo al final, en un texto agregado a mano de Zubiri donde dice: «Necesitamos, pues, buscar el fundamento de mi relativo ser absoluto. Y en esta búsqueda se inscribe justamente el problema de Dios. Es el tema de la Segunda Parte de nuestra investigación: el problema de la realidad divina» ${ }^{13}$. La expresión "problema de Dios» se deja explícitamente para la Segunda Parte. Lo que aparece en esta última versión de la Primera Parte es la expresión «problema de la fundamentalidad» que, además, como ya señalamos, constituye el título de un apartado nuevo que no se encontraba en la redacción del curso de Roma, que es la primera versión del libro. La expresión «problema de la fundamentalidad» parece ser introducida, entonces, para intentar evitar los diversos matices que tiene la palabra «Dios». La expresión "problema de Dios» puede usarse en este plano de descripción, pero sólo como «nominalmente» idéntica a «problema de la fundamentalidad». En la Segunda Parte del libro, Zubiri debe demostrar que esta identificación no es sólo nominal sino «real», que es el segundo sentido de la expresión "problema de Dios», según vimos en la cita anterior. Sólo en sentido nominal, entonces, en el plano de la descripción primaria, puede llamarse al problema de la fundamentalidad, el «problema de Dios». La filosofía teológica o teologal puede llamarse también, en este sentido, filosofía de la fundamentalidad o filosofía de la religación, es decir, de cómo el hombre hace su vida fundado en «la» realidad.

\subsection{Problematismo intelectivo y opcional a la fundamentalidad de lo real}

Esta religación al poder de lo real, a la fundamentalidad, es «problemática» o ambivalente. Ello porque son las cosas reales las que nos impelen a tener que realizarnos, pero ninguna de ellas es «la» realidad. Debemos averiguar «intelectivamente» cuál es el «contenido concreto» de esa realidad-fundamento para poder «optar» por una forma de realidad en mis acciones. Estos dos momentos (intelección y volición) originarán las diversas actitudes ante el problema de

12 Así Zubiri lo dice en el curso «El problema teologal del hombre: Dios, religión, cristianismo» de 1971, "Basta abrir un libro de historia de las religiones; ¿qué se entiende por Dioses? Efectivamente, eso. No solamente unos seres supremos, sino unos seres supremos a quienes el hombre puede dirigirse de una cierta manera, de quienes puede recibir ayuda, en quienes puede uno ayudarse, con éxito o sin él, pero, en fin, esto es lo que entendemos por Dios»: Zubiri, X. (2015). El problema teologal del hombre: Dios, religión, cristianismo. Madrid: Alianza, p. 112.

13 Zubiri, X. . (2012). El hombre y Dios, op. cit., p. 114. 
Dios o de la fundamentalidad. Será el tema que profundizaremos en el último punto.

\section{Diversas actitudes ante el problema de la fundamentalidad o de Dios}

Para Zubiri hay diversas actitudes ante el problema de Dios (al problema del fundamento de lo real y de mis acciones) lo cual origina diversas soluciones. Toda actitud posee dos momentos:

a) Momento racional: Consiste en darle «contenido concreto» a la fundamentalidad ya inteligida, es decir, conocer racionalmente qué es la fundamentalidad. Así, todos tienen acceso a la fundamentalidad, la diferencia está en el despliegue racional de esa intelección. Por ejemplo, identificar tal fundamentalidad con una determinada concepción de Dios.

b) Momento volitivo u opcional: La aprehensión de la fundamentalidad posee no sólo un aspecto «intelectivo racional», sino también un aspecto ineludiblemente volitivo, de "opción». Para aclarar esto, ante todo, tengamos en cuenta que la volición es, para Zubiri, una «determinación en la realidad» ${ }^{14}$ que posee dos momentos. Por una parte, en la volición como «determinación» estoy tomando una opción por sobre otras. Elijo, por ejemplo, comer, caminar, etc. Pero también, por otra parte, estoy eligiendo para mí una «forma de ser real» por sobre otras. No sólo elijo, por ejemplo, caminar, sino «ser caminante», etc. "La volición es última y radicalmente la determinación de una posibilidad como modo de mi ser sustantivo» ${ }^{15}$.

Ahora bien, hay dos modos de realidad que pueden actualizarse ante la intelección. Si lo que se presenta es una «realidad-objeto», uno puede o no entregarse a esa realidad. Aquí lo real aprehendido en cierta forma es anterior a la volición. Pero en distinto caso nos encontramos cuando lo que se actualiza es una realidad-fundamento. La realidad-fundamento de lo real en tanto real no es algo que esté meramente "ahí», sino que su realidad, «siempre presente», consiste en «impelerme» a tomar una opción frente a ella. Esta opción ineludible es lo que Zubiri llama «voluntad de fundamentalidad». Para Zubiri, la voluntad de fundamentalidad es el «principio radical de una actitud [teísmo, ateísmo, etc.] que desde sí misma se despliega en proceso intelectivo y opción ${ }^{16}$. Esta volición radical es principio de todo el «proceso sentiente» en dos momentos. En primer lugar, es principio de «intelección» ulterior, como el logos y la razón. Así Zubiri nos dice: «La voluntad de fundamentalidad no es meramente un acto consecutivo a la intelección de la realidad-fundamento, sino que es una voluntad que pone

14 ZuBiri, X. (1980). Inteligencia y realidad, Madrid: Alianza, p. 283.

15 ZuBiri, X. (2012). El hombre y Dios, op. cit., p. 257.

16 Ibíd., p. 299. 
en marcha el proceso intelectivo» ${ }^{17}$. La voluntad de fundamentalidad, para Zubiri, ciertamente estaría fundada en la aprehensión primordial de la fundamentalidad (aquí no hay opción), pero su carácter problemático nos abre a tener que tomar una "opción» concreta dentro del momento mismo de intelección, por ejemplo, desde qué aspectos vamos a intentar «describir» la fundamentalidad, qué esbozo vamos a forjar para intentar "conocerla», etc. Hay un momento de volición en el despliegue «intelectivo» del problema de Dios. En segundo lugar, esta volición radical, apoyándose en lo actualizado por todo el proceso intelectivo, es también principio de «apropiación» opcional de un modo de «entrega» a la fundamentalidad. Este momento de entrega está relacionado con la fe. La fe para Zubiri es «la entrega personal a una realidad personal en cuanto verdadera $»^{18}$. La fe, por tanto, no es aquí una mera creencia, algo en el fondo intelectivo. No hay fe, por ejemplo, en los átomos o la evolución. Tampoco, en rigor, es fe la admisión a «lo» que se dice. La fe es aquí un momento volitivo, de entrega a una realidad personal. En el texto «El despliegue del problema de Dios» de la nueva edición de $E l$ hombre y Dios, la fe parece ser un momento de toda actitud, por ejemplo, del ateísmo. Eso no es tan claro en las últimas versiones recientemente publicadas. En el curso de Roma de 1973, la fe sólo aparece explícitamente en la actitud teísta. Si es así, la fe sería sólo un tipo especial de entrega. Habría que distinguir, tal vez, entre la «entrega» (que sería algo ineludible, dado el carácter impelente de la fundamentalidad) y la fe, que presupondría la fundamentalidad entendida como realidad personal. No es algo que quede claro en los textos últimos que se nos han conservado.

La unión de estos dos momentos (intelectivo y volitivo) origina, pues, las diversas actitudes ante la fundamentalidad. Por ejemplo: teísmo, ateísmo, indiferentismo, agnosticismo, etc. Cada una de estas actitudes origina su propio camino, método o "vía» de conocimiento que puede desembocar o no en una prueba. Para Zubiri, método «es un abrirse paso hacia el fundamento. Método es por tanto vía del conocer en cuanto tal» ${ }^{19}$. Cada actitud, entonces, prefija el rumbo de las vías para verificar la fundamentalidad. Así Zubiri en el manuscrito de la Segunda Parte de 1983 nos dice: «La búsqueda [de la fundamentalidad] puede estar inspirada en algo previo que llamaremos actitud. Cada dirección de búsqueda constituye una actitud $»^{20}$.

Ahora bien, aquí hay que distinguir entre lo que cada actitud diría de sí misma (en general, las actitudes entienden por Dios un ser supremo transcendente al mundo) y cómo las interpreta, en el fondo, Zubiri. Zubiri, recordemos, entiende a Dios como fundamentalidad. Así, para Zubiri, independientemente de lo que diga cada actitud, todo hombre tiene intelección de la fundamentalidad la cual impele

17 Ibid., p. 271.

18 Ibid., p. 308.

19 Zubiri, X. (1983). Inteligencia y razón, Madrid: Alianza, p. 203.

20 Zubiri, X. (2012). El hombre y Dios, op. cit., 123. 
inexorablemente a su apropiación volitiva. La diferencia está, en el fondo, en el tipo de «conocimiento» que se tenga sobre esta fundamentalidad y su modo de entrega.

Por último, hay que destacar que, independientemente de la veracidad de estas vías racionales, se entiende que las diferencias de actitudes no se refieren, en rigor, a diferencias de acciones ocasionales (por ejemplo, el teísta va a misa, el ateo no, etc.), sino a diferencias que se expresan en cada una de las acciones cotidianas. Nuevamente hay que recordar que el fundamento se intelige y opta en cada acción cotidiana del hombre.

Veamos ahora algunas de estas actitudes.

\subsection{Ateísmo o la vía de la facticidad}

En esta actitud, se niega la existencia de Dios como ser supremo y su entrega a él. El ateísmo aparece, a primera vista, como un momento de «negación» intelectiva y volitiva de Dios. Pero aquí hay dos posturas que hay que distinguir cuidadosamente. Ante todo, existe la postura atea como la negación de todas o algunas de las ideas o conceptos conocidos que se han afirmado sobre Dios. Es una especie de «ateísmo-contra». A esta postura sería mejor llamarla "antiteísmo» o algo parecido. Grandes filósofos han apuntado, de alguna manera, a esta línea como Marx, Nietzsche, etc., reclamando, por ejemplo, contra un Dios determinado. Más aún, un monoteísta podría ser «antiteísta» de una determinada postura teísta como la politeísta, etc. Habría así antiteístas relativos a determinadas concepciones de Dios y antiteístas absolutos de todas las concepciones conocidas de Dios, postura que generalmente suele llamarse ateísmo. Ahora bien, esto no es exactamente lo que entiende Zubiri por ateísmo. Así, nos dice: "No se trata de un ateísmo que fuera "contra" la realidad de Dios. El ser "contra" no es esencial al ateísmo. Es cada día mayor el número de aquellos cuyo ateísmo no va contra nada ni contra nadie» ${ }^{21}$.

Para Zubiri, desde el punto de vista de Dios como «fundamentalidad», hay implícitamente en el ateísmo un momento "positivo» intelectivo y opcional. Todos tenemos acceso a la aprehensión de la realidad como fundamentalidad, la cual impele a esbozar un contenido racional último y una entrega ante ello. Esto no es propio del ateísmo sino de todo hombre. Lo propio del «ateísmo» es concebir concretamente esa fundamentalidad como la facticidad del ser y ante eso hay entrega: es la vida como autosuficiente. Según «El despliegue del problema de Dios», esto constituiría la fe del ateo, pero eso no aparece explícito en versiones ulteriores. Sobre el ateísmo, Zubiri dice lo siguiente en su curso de Roma:

«A esta actitud del ateo corresponde un proceso intelectivo que termina en la pura facticidad del ser y un modo de apropiación peculiar: el que cree que su ser relativo no es más que la facticidad de aquello que se es y tiene una actitud de apropiación para la vida que consiste en la autosuficiencia» ${ }^{22}$.

$21 \quad$ Ibid., p. 294.

22 Ibíd., p. 441. 
En síntesis, lo propio de la actitud atea es, pues, una postura intelectual y volitiva completamente positiva que encuentra cumplimiento en la facticidad del ser: es lo que Zubiri llama la «vía de la facticidad». El momento a-teo mienta sólo el momento conceptual de negación de una determinada idea de Dios, lo que yo he llamado aquí «antiteísmo» para mayor claridad. La vía atea, para Zubiri, es en realidad una vía positiva por la cual un hombre se hace persona afirmándose intelectiva y volitivamente en la facticidad de la realidad, pero en tanto que es. Por ello, esta vía, para Zubiri, carece de ultimidad pues el ser se funda en la realidad. Es un tema que no podemos profundizar aquí.

\subsection{AgNosticismo}

Se suele decir que el agnóstico niega que pueda «conocerse» con certeza a Dios como ser supremo ${ }^{23}$. Por ello, también suspende la fe. Pero, para Zubiri, al igual que en el ateísmo, hay en el agnosticismo un momento positivo intelectivo y opcional: la intelección y volición sobre la fundamentalidad de lo real. En el "Curso de Roma» nos dice: "Hay" una actitud que consistiría en partir precisamente de la inteligencia que busca y decir que en la inteligencia ciertamente hay el área de la fundamentalidad de lo real, pero esta fundamentalidad no puede ser término de un conocimiento ${ }^{24}$. Más tarde, en la última redacción manuscrita, nos dice: «Hay otra actitud distinta: partir de la inteligencia que busca la fundamentalidad de lo real, pero no la encuentra. Aquella intelección es una $\dot{\alpha} \gamma v \omega \sigma i \alpha$ : es el agnosticismo» ${ }^{25}$.

Aquí Zubiri parece sostener que el agnóstico, que ciertamente intelige la fundamentalidad, llega a la conclusión intelectiva que la fundamentalidad, que le «impele» a buscar, no coincide con ningún concepto conocido de un Dios supremo y se frustra de seguir buscando. Concluye así que Dios no puede ser conocido. Por tanto, llega a un «conocimiento suspensivo» por frustración. No es falta de conocimiento de la fundamentalidad sino conocimiento suspensivo por frustración. Por otra parte, el agnóstico, desde el punto de vista volitivo u opcional es calificado por Zubiri como un «buscador sin término ${ }^{26}$.

\subsection{TEÍSMO}

En esta actitud, se afirma que Dios existe y, además, hay entrega a Él en la vida propia ${ }^{27}$. Para Zubiri, nuevamente esta actitud se apoya sobre la intelección y voluntad de fundamentalidad como las actitudes anteriores. Lo propio

${ }^{23}$ Beck lo define así: «Este escepticismo [relativo a Dios] mantiene que el espíritu humano está capacitado fundamentalmente para la verdad, pero afirma, no obstante, la imposibilidad de un conocimiento filosófico de Dios (...) Esta teoría es el llamado agnosticismo» (H. Beck. (1968). El Dios de los sabios y los pensadores. Madrid: Gredos, pp. 40-41).

24 Zubiri, X. (2012). El hombre y Dios, op. cit., p. 438.

25 Ibíd., p. 127.

26 Cfr. Ibid., pp., 127, 438.

27 Beck lo define así: «La afirmación de la existencia de un Dios personal superior al mundo se llama teísmo» (H. ВЕсK. (1968). El Dios de los sabios y los pensadores, op. cit., p. 57). 
de esta actitud es conducir a un particular conocimiento y/o volición de la fundamentalidad. Dentro del teísmo hay distintas vías.

a) Una vía es llegar a afirmar racionalmente la existencia de dios o dioses que no tienen relación con el hombre. Son los llamados «dioses ociosos». Zubiri lo explica así:

«Un dios ocioso es un dios real, pero que no interviene en la vida de la persona; la vida del hombre no está entonces trazada en función de Dios. Es la realidad-fundamento de Dios, reducida a realidad-objeto (...) Y no es sólo el caso de Aristóteles. Es en el fondo la situación de muchísimos hombres actuales, cada vez en mayor número. Su ateísmo es más bien el teísmo de un Dios ocioso. Admiten la existencia de Dios, de una causa primera, admiten incluso su conocimiento estrictamente demostrativo, pero es para ellos meramente una realidad en sí, que no interviene en la vida ni respecto de la cual tiene sentido hablar de entrega en fe» ${ }^{28}$.

Aquí, el momento racional y volitivo de fundamentalidad pretenden, de algún modo, ser separados. Aquí se afirma que hay conocimiento de Dios, pero no entrega. A un Dios así no se le reza, es fundamento último, pero no posibilitante. Es lo que ocurre en algunas religiones y en Aristóteles. Es una vía, en cierto modo, «deísta» de la fundamentalidad.

b) Hay otra vía en que ocurre, en cierta forma, lo contrario; el hombre no posee conocimiento estricto de la fundamentalidad como Dios, pero sí entrega y fe en Él. Es una vía que Zubiri llamaría «gnóstica» y que nosotros podríamos llamar aquí tal vez «fideísta». Así, Zubiri nos dice:

«El hombre, en efecto, puede alojar (por así decirlo) más o menos espontáneamente, en el ámbito de lo real a que nos estamos refiriendo, la realidad absolutamente absoluta de Dios (...) Hay entonces una intelección, una gnosis (en el sentido etimológico del vocablo y no como designación del gnosticismo en la historia de las religiones). Es la intelección del ámbito real de la fundamentalidad de lo real, pero una intelección que no aboca a un estricto conocimiento sino a una fe. Es, en definitiva, el caso de la casi totalidad de los hombres que creen en Dios: no se hacen cuestión de justificar racionalmente su realidad ${ }^{29}$.

En este caso, el hombre intelige la fundamentalidad (gnosis), pero no la conoce con rigor. Sin embargo, ello no le impide tener una entrega o fe. Esta vía es muy parecida a la vía agnóstica en el sentido en que ambas vías poseen «gnosis» entendida como intelección de la fundamentalidad (la «agnosis» del agnosticismo no es negación de esa intelección), pero no terminan en un conocimiento de Dios. La diferencia está en la «entrega» desplegada.

c) Finalmente, está la vía teísta que podríamos llamar «religiosa», que desemboca en un conocimiento y una entrega a Dios. Dentro de esta vía hay, a

28 ZuBIRI, X. (2012). El hombre y Dios, op. cit., p. 274.

29 Ibid., p. 284-285. 
su vez, múltiples caminos como el monoteísmo, politeísmo y el panteísmo. Zubiri siguió la vía monoteísta que llamó «vía de la transcendencia» ${ }^{30}$. Como seguir esta vía es una opción y afirmación racional, debe justificarse, al menos para un filósofo. Zubiri ha construido su propia vía, prueba o argumento racional a Dios. Lo fue meditando y corrigiendo hasta su muerte. El argumento final que utilizó Zubiri es a través de la vía de la religación o realidad. Esta prueba o argumento no pretende ir a Dios como algo que está fuera de la aprehensión, sino venir de Él. El argumento de la existencia de Dios en Zubiri no pretende basarse en lo que «sabemos» de Dios por revelación. No pretende demostrar, por ejemplo, que Dios es creador del mundo. El argumento se basa en la «aprehensión de fundamentalidad», de realidadfundamento, una aprehensión que llamamos nominalmente «de Dios» y que intentamos probar a través de nuestra experiencia de hacernos persona. Por ello, Zubiri nos dice:

«Me gustaría afirmar que efectivamente el hombre encuentra a Dios no reflexionando sobre el mundo cósmico ni reflexionando sobre sus fenómenos mentales: el hombre encuentra a Dios en una dimensión distinta que, a mi modo de ver, abarca ambas cosas, a saber, haciéndose persona ${ }^{31}$.

\section{Bibliografía CONSUltadA}

BЕск. H. (1968). El Dios de los sabios y los pensadores. Madrid: Gredos.

GonzÁlez. A. (2005), «La vía cósmica hacia Dios según Zubiri», The Xavier Zubiri Review, 7, pp. 91-107.

Solari. E. (2009), «El argumento cosmológico de Zubiri», Revista Filosófica, Vol. 65, pp. $115-141$.

Zubiri. X. (1969). «Estructura de la metafísica», Archivo Zubiri (inédito).

- (1980). Inteligencia y realidad. Madrid: Alianza.

- (1983). Inteligencia y razón. Madrid: Alianza.

- (1993). El problema filosófico de la historia de las religiones. Madrid: Alianza.

- (1994). Los problemas fundamentales de la metafísica occidental. Madrid: Alianza.

- (2012). El hombre y Dios. Nueva Edición. Madrid: Alianza.

- (2015) El problema teologal del hombre: Dios, religión, cristianismo. Madrid: Alianza.

Pontificia Universidad Católica de Valparaíso

esteban.vargas@ucv.cl

ESTEBAN VARGAS

[Artículo aprobado para publicación en este número extraordinario en noviembre de 2014]

30 Cfr. Zubiri, X. (1993). El problema filosófico de la historia de las religiones. Madrid: Alianza, p. 140.

31 ZuBiri, X. (2012). El hombre y Dios, op. cit., p. 456. 